\title{
Displasia cleidocraneal: Revisión y estudio de las carácterísticas clínicas y radiográficas de una familia chilena
}

\section{Cleidocranial displasia: review and study of the clinical and radiographic features in a chilean family}

Alejandra Castro Araya ${ }^{1}$

Enrico Escobar López ${ }^{2}$

Gloria García Moreno ${ }^{3}$

\begin{abstract}
Cleidocranial Dysplasia (CDD) is a rare syndrome usually caused by an autosomical dominant gene with high penetrance and variable degree of expressions. This condition is usually caused by a mutation of the Core Binging Factor- $\alpha 1$ gene, located at chromosome $6 \mathrm{p} 21$. This gene encodes a protein necessary for the correct functioning of osteoblast cells, however, $40 \%$ of cases of CDD appear spontaneously with no apparent genetic cause. CDD Primarily affecting bones undergoing intramembranous ossification characterized by clavicular aplasia or hypoplasia, retarded cranial ossification, multiple impacted permanent teeth, supernumerary teeth, short stature, delayed closure of the sagittal fontanelles and a variety of other skeletal abnormalities.
\end{abstract}

A family case of CDD is presented. A mother and two children were referred to the Oral Pathology Service of the University of Chile. In all three cases, a radiological series was performed over the entire body. Generalized dysplasia in bones (clavicular aplasia), prolonged retention of primary teeth and delayed eruption of permanent, as well as supernumerary teeth was diagnosed. Clinical and Radiological findings are presented.
Key words: Cleidocranial Dysplasia, clavicular aplasia or hypoplasia, supernumerary teeth, skeletal abnormalities.

\section{Introducción}

La Displasia Cleidocraneal (DCC), también conocida como disostosis cleidocraneal, corresponde a un raro síndrome de transmisión autosómica dominante con alta penetrancia y expresividad clínica variable. Causada por mutaciones en el Gen CBFA1/RUNX2 factor de transcripción que activa la diferenciación osteoblástica ubicado en el cromosoma 6p21. Fue descrita por Marie y Sainton en 1898, caracterizada por anomalías en las clavículas, retraso en el cierre de fontanelas, suturas abiertas, cráneo braquicefálico, dientes supernumerarios, estatura baja y una variedad de cambios esqueléticos como trastornos de la osificación de huesos largos, pelvis y columna vertebral ${ }^{2}$. Considerada como una displasia esquelética, corresponde a una enfermedad de origen genético, muy poco frecuente en la población, con una prevalencia de $1 / 1.000 .000^{3}$. $\mathrm{Su}$ diagnóstico se basa casi exclusivamente en las carácteristicas clínicas y radiológicas que presentan los pacientes.

\footnotetext{
${ }^{1}$ Departamento de Patología, Facultad de Odontología, Universidad de Chile 
Nuestro objetivo es presentar el caso clínico de un niño de 12 años, que consultó en el Servicio de Diagnóstico y Urgencia de la Facultad de Odontología de la Universidad de Chile, derivado del Hospital San Luis de Buin (localidad rural de Chile), con diagnóstico de Displasia Cleidocraneal. Este estudio se complementa con la historia clínica familiar, de la madre de 39 años de edad y la hermana de 7 años. En los tres casos es posible observar las características clásicas de este síndrome.

\section{Caso Clínico}

Se presenta el caso clínico de un niño de 12 años, que consultó en nuestra Facultad por presentar retraso en la erupción dentaria. En la anamnesis remota familiar encontramos en sus abuelos maternos, actualmente vivos, antecedente de hipertensión arterial controlada. Su madre y hermana, presentan características fenotípicas similares. Existe el antecedente neurológico de cierre tardío de la fontanela anterior y tendencia a la formación de queloides. Al examen físico general observamos la relación peso- talla alterada, con una estatura mas baja de la norma, manos angostas con dedos finos y largos, hipertricosis e hipertelorismo (figura 1).

Es posible observar además hipoplasia de la cintura escapular, hombros caídos y tórax acampanado. Se evidencia una hipelaxitud de los hombros con hipoplasia de clavículas que permite aproximar ambas cabezas humerales hacia la línea media anterior del tórax (figura 2).

Se solicita examen radiográfico complementario de tórax. La radiografía PA torácica nos revela las características radiográficas de este síndrome. Tórax acampanado, hipoplasia de clavículas, escápulas pequeñas, cortas y aladas, con un parénquima pulmonar de aspecto normal (figura 3).

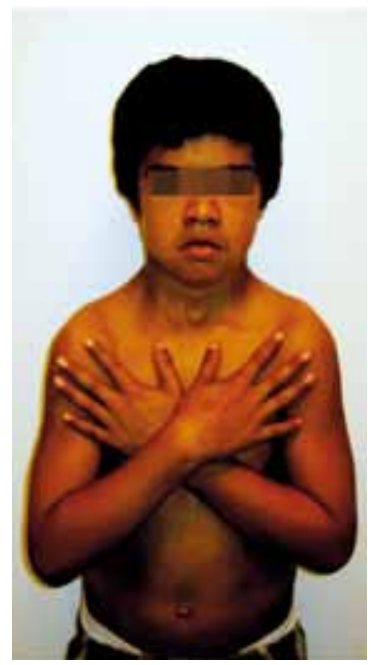

Figura 1.

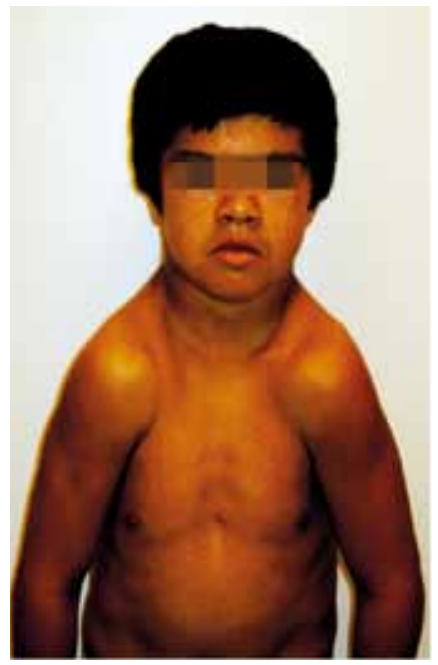

Figura 2.

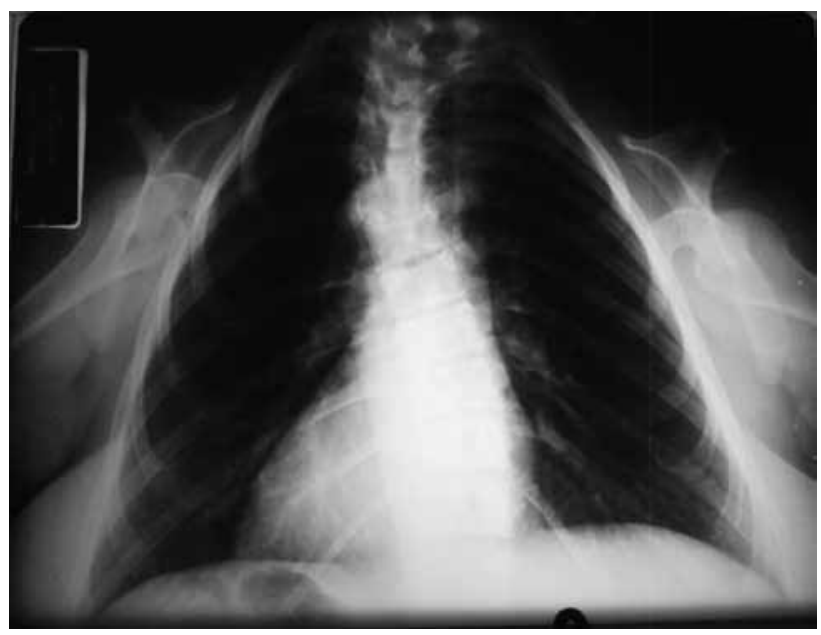

Figura 3.

Realizamos el examen de cabeza y observamos un aumento progresivo del perímetro cefálico, braquicefalia, hipertelorismo, hipertricosis, presencia de hendiduras antimongoloideas, falta del desarrollo del tercio medio e inferior (aplasia maxilar superior) y tendencia a clase III esqueletal (observar figura 1). Complementamos nuestro estudio solicitando radiografía lateral de cráneo (figura 4).

Examen intraoral: se pesquisa un retraso en la erupción dentaria definitiva con permanencia de piezas temporales, agenesia de laterales superiores y policaries. Paladar Ojival, prognatismo 
y clase III esqueletal (figuras 5, 6 y 7). Se solicita ortopantomografia visualizando permanencia de la dentición temporal, retraso en la erupción dentaria definitiva, agenesia de laterales, supernumerarios múltiples, e imagen compatible con odontoma a nivel de los incisivos centrales (figura 8).

Similares características clínicas y radiográficas fueron encontradas en la madre y hermana (figura 9).

Al examen clínico presenta: facie progénica, hipertelorismo, hipertricosis, agenesia de piezas dentarias, permanencia de dentición temporal, alteración de relación peso - talla. Se indica estudio imagenológico: radiografía de tórax, ra-

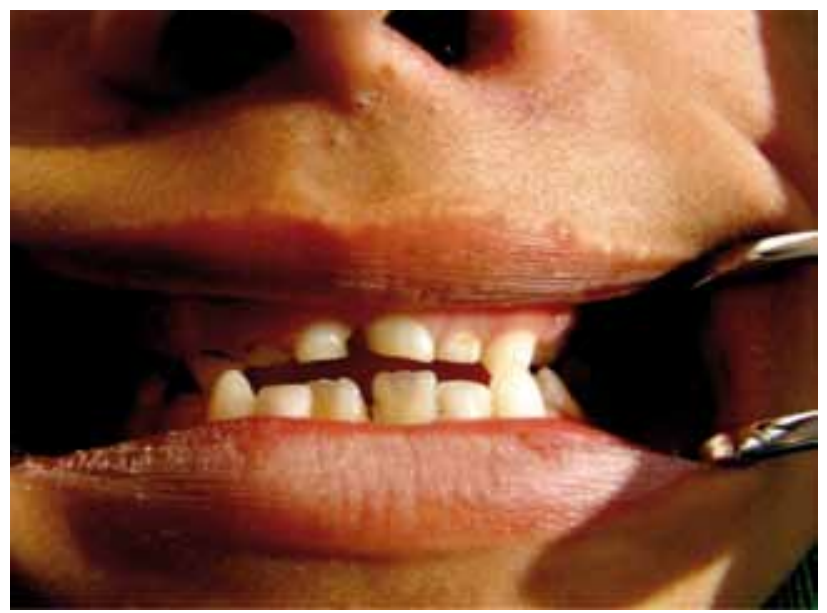

Figura 5.

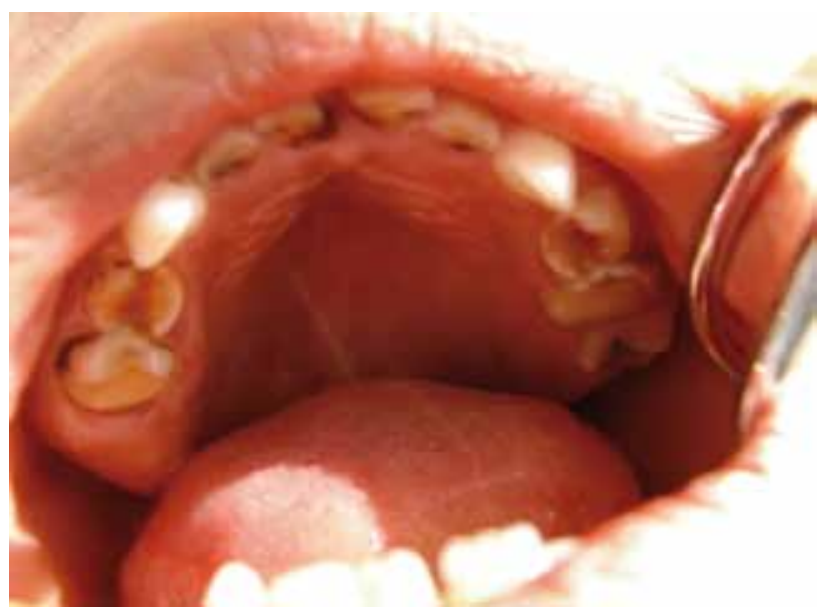

Figura 7.

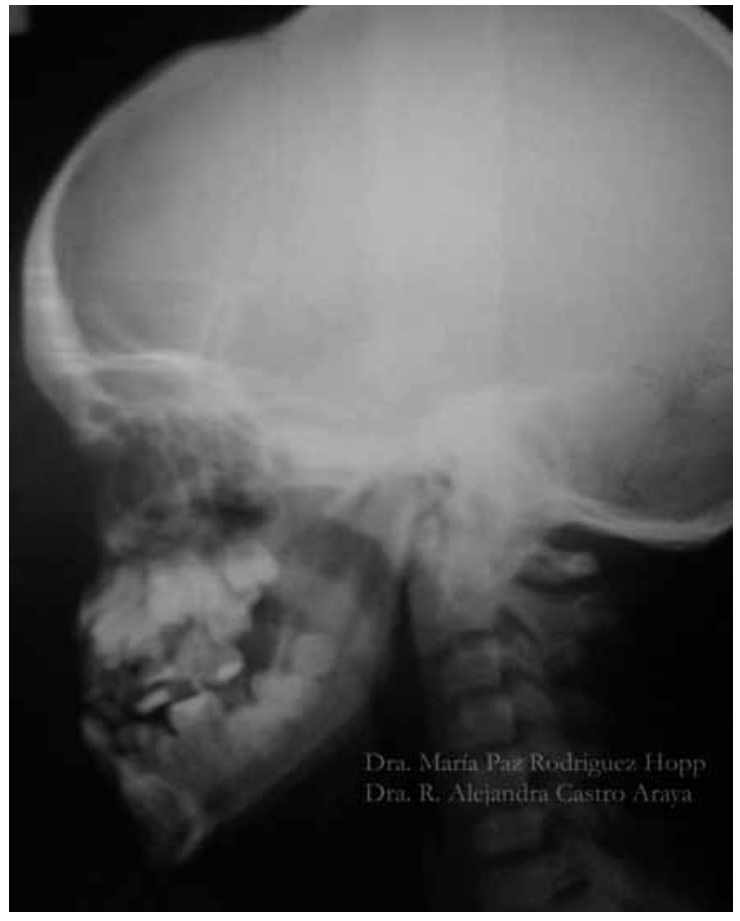

Figura 4.

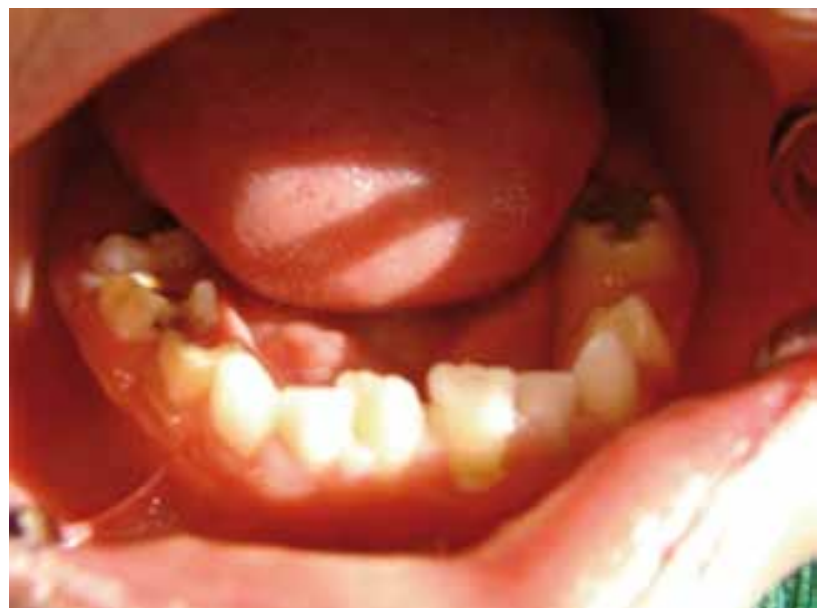

Figura 6.

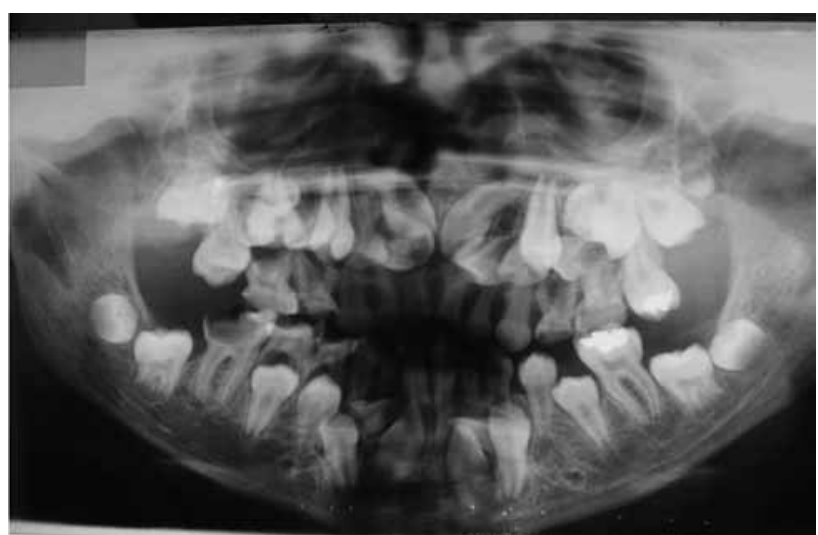

Figura 8. 

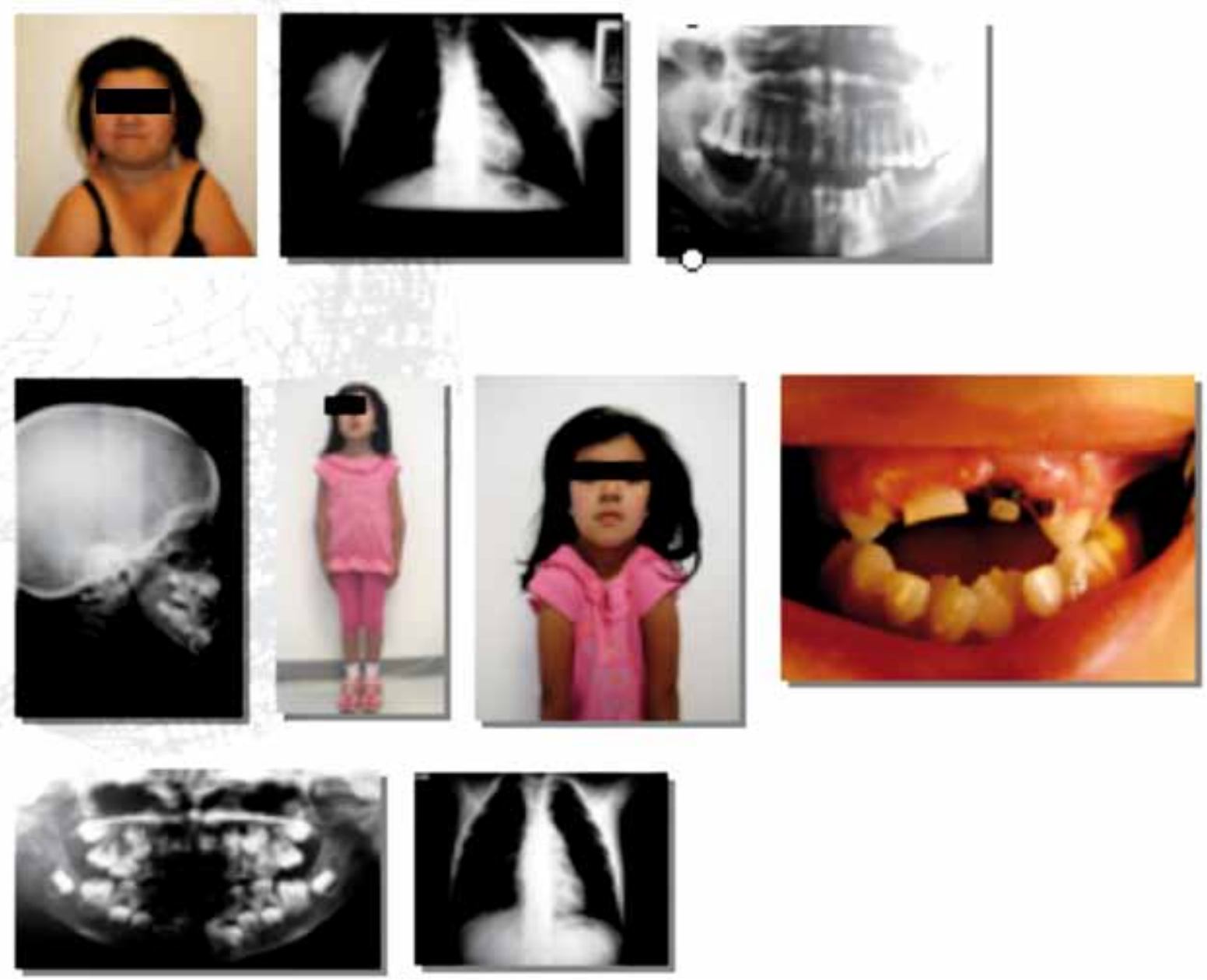

Figura 9.

diografía panorámica y cefalometría. Se evidencia aplasia clavicular, permanencia de dentición primaria y erupción tardía de dentición permanente. Este estudio se complementa con la historia clínica familiar, de la madre de 39 años de edad y la hermana del paciente con 7 años de edad. En los tres casos es posible observar las características clásicas de este síndrome.

\section{Discusión}

La displasia Cleidocraneal corresponde a un síndrome de origen autosómico dominante, que afecta al sistema esquelético. Se caracteriza por aplasia o hipoplasia de las clavículas, malformaciones craneofaciales y óseas características, tales como fontanelas amplias y suturas abiertas con retraso en su cierre. Estos pacientes presentan inteligencia normal, estatura disminuida y varias manifestaciones bucales. Existe un grave retraso en la erupción de dientes permanentes, muchos dientes no erupcionan y por otro lado la aparicición de múltiples dientes supernumerarios resulta ser habitual. Souza y otros autores4, plantearon que las anomalías dentarias, dientes supernumerarios, retención de dientes y la no erupción de dientes permanentes ocurren con mucha frecuencia. El diagnóstico de displa- 
sia cleidocraneal se basa casi exclusivamente en elementos clínicos y radiológicos. La evaluación clínica, debe estar orientada a los antecedentes recolectados a través de la anamnesis personal y familiar, lo que puede sugerir una base genética del problema. La descripción de rasgos dismórficos, la evaluación antropométrica con la evaluación de peso, talla y perímetro cefálico, evaluación del desarrollo global del niño y exámenes complementarios, tanto genéticos como radiológicos, permiten la confirmación del diagnóstico. Si bien es cierto tratamos con un cuadro de evolución crónica y muchas veces progresivo, que no presenta un tratamiento curativo, es importante el diagnóstico a temprana edad, con la finalidad de actuar convenientemente sobre los trastornos que podrían presentarse posteriormente tales como las alteraciones dentales, maxilares y esqueletales. El manejo adecuado implica un trabajo en equipo de salud multidisciplinario.

\section{Bibliografía}

1. Marie P, Sainton P. La dysostose cleidocranienne hereditaire. Bull Soc Med Hop ( Paris) 1898;15;436.

2. Santolaya JM, Delgado A. Displasias óseas. Ed.Salvat 1998.

3. Cooper S, Flaitz C, Johnston D. A natural history of cleidocranial dysplasia. Am J Med Gen 2001; 104:1-6

4. Souza LC, Varanda AP, Villa N. Cleydocranial dysostosis: report of 3 cases in the same family. Rev Paul Pediatr 1987;5 (17): $72-4$ 